\title{
ECONOMIC DISCIPLINES IN THE CONTEXT OF THE NEW LIST OF JOURNALS - NETWORK ANALYSIS
}

\author{
Tomasz OWCZAREK \\ Silesian University of Technology, Faculty of Organization and Management, Department of Economics and \\ Informatics, Poland; tomasz.owczarek@polsl.pl, ORCID: 0000-0003-2532-4127
}

Purpose: The aim of this article is an attempt to characterize economic disciplines, i.e. economics and finance, as well as management and quality studies, based on their assignments to scientific journals, and to identify the place of these two disciplines in relation to each other and their links with other disciplines.

Design/methodology/approach: Quantitative and network analysis methods were used for graphical representation and description of the complex relationships. The analysis was based on the data published on 31 July 2019, constituting a list of scientific journals.

Findings: The results confirm a strong link between the two disciplines, but they also show some differences between them. The discipline of economics and finance is particularly strongly linked with the discipline of social and economic geography and spatial management. This is not the case for management and quality studies, which is more closely linked to disciplines outside social sciences.

Research limitations/implications: The results are based only on a quantitative approach to the relationships between disciplines, therefore, they should not be used to draw too farreaching conclusions, e.g. on the differences between these two disciplines in methods, subject matter or facilities under analysis. Further research may take into account, for example, different research trends and approaches within the disciplines themselves.

Originality/value: Presented network approach shows the connections between scientific disciplines in a new holistic way. The results could be especially interesting for researchers whose studies are interdisciplinary.

Keywords: scientific disciplines, network analysis.

Category of the paper: Research paper.

\section{Introduction}

In 2018, a new classification of scientific fields and disciplines was introduced in Poland. The three-tier system (areas of knowledge, fields of science, scientific disciplines), in force since 2011, has been replaced by a new two-tier system, based, to a large extent, 
on the classification of scientific disciplines according to the Organization for Economic Cooperation and Development (OECD). In the new division, the existing areas of knowledge have become fields of science ${ }^{1}$, while the new disciplines have been consolidated from the existing fields and disciplines, which has significantly reduced their number. According to the announcements of the Ministry of Science and Higher Education, the new classification was to be as close as possible to the OECD system (which was the starting point for its development) ${ }^{2}$, while maintaining certain differences resulting from the postulates of the academic community. These differences can be observed, for example, in the case of sciences belonging to the field of economic sciences in the previous classification. It consisted of the following four disciplines: economics, finance, management studies and commodity science. In the OECD classification, there is one discipline covering these areas: economics and business ${ }^{3}$. In the new division of fields and disciplines, adopted by the Ministry of Science and Higher Education, two disciplines have been introduced:

- economics and finance, which covered two previous disciplines: economics (excluding the scope of spatial management) and finance,

- management and quality studies, including former management studies in the field of economic sciences ${ }^{4}$ and commodity science (in the scope of quality and product management) $)^{5}$.

At the time when the previous classification of sciences was in force, there was a constant discussion among Polish scientists engaged in economic sciences about the identity of the disciplines that comprise them. For example, M. Gorynia and T. Kowalski drew attention to the differences between economics, management and finance, among which they mentioned the area of interest and the method of creating a particular discipline and method of practicing science. These authors emphasized, however, that "more fruitful and practical in terms of cognition seems to be the recognition of their complementarity, while, at the same time, noting their distinctiveness and respecting their specificity" (Gorynia, and Kowalski, 2013). A more radical approach was presented by S. Sudoł, according to whom management studies

\footnotetext{
${ }^{1}$ With two exceptions: the area of exact sciences and the area of natural sciences were merged into one field of natural sciences, while the field of theology, which in the former division was in the area of humanities, remained a separate field in the new division.

2 The Ministry of Science and Higher Education, New regulation on disciplines - a reliable evaluation of scientific research, 20.09.2018 (https://www.gov.pl/web/nauka/nowe-rozporzadzenie-ws-dyscyplin-to-rzetelna-ocenabadan-naukowych, accessed on: 02.11.2019).

3 OECD, Revised field of science and technology (fos) classification in the frascati manual, 2007 (https://www.oecd.org/science/inno/38235147.pdf, accessed on 02.11.2019).

${ }^{4}$ The division in force until 2018 also included the discipline of "management studies" belonging to the field of humanities. This discipline has been assigned to the new discipline of "political science and public administration".

${ }^{5}$ The scope of former economics related to spatial management entered the new discipline of "social and economic geography and spatial management", while the remaining scope of the former discipline of commodity science was assigned to the disciplines of "nutrition and food technology" and "materials engineering" (the Ministry of Science and Higher Education, New regulation on disciplines..., table enclosed to the communication: https://www.gov.pl/attachment/df63a7c2-3957-4ebc-8940-73c936b81dec, accessed on: 02.11.2019).
} 
should be an independent field of science, because solving management problems often requires their exposure from the position of many disciplines that go beyond economic sciences. The author also quotes L. Krzyżanowski here, drawing attention to the interdisciplinary nature of the problems studied by management studies, but, at the same time, emphasizing their independence and distinctiveness in the classification of sciences (Sudoł, 2016).

Regardless of the scientists' opinions, the separation of two disciplines from the previous classification in the field of economic sciences (contrary to the OECD system) seems understandable, taking into account the existing powers of Polish universities to award academic degrees. As a result, in accordance with the new classification, the right to confer doctoral degrees in economics and finance remained primarily in the group of non-technical universities (29 units, including only one technical university). On the other hand, in the group of units with the right to award doctoral degrees in management and quality studies (30 units), there are as many as 9 technical universities (five of which have the right to award the degree of doktor habilitowany) ${ }^{6}$. Lack of division into economics and finance, as well as management and quality studies, would result in the fact that these universities would acquire the right to decide on promotion in new areas of science by an administrative decision.

However, such a division may cause some dilemmas and difficulties in the context of the new system of evaluation of units. In the previous system, basic units of universities (i.e. most often faculties) were evaluated, which were compared with each other within the so-called joint assessment groups (GWO). The disciplinary affiliation of the publication of a scientist employed in such a unit was irrelevant - the scientist "contributed" to the unit's result with their publications, regardless of their assignment to disciplines. The new Act on Higher Education and Science of 20 July 2018 amended those principles by introducing evaluation of scientific activity at universities within each discipline. Therefore, each researcher is obliged to declare the discipline in which they conduct scientific activity. Additionally, on 25 January 2019 , teams of experts representing particular scientific disciplines were appointed to assign disciplines to scientific journals included in international databases. This specification is to be used in future evaluation to assess whether a particular publication can be automatically included in the achievements of a particular discipline. As a consequence of all this, despite the fact that the previous four disciplines in economic sciences have been consolidated into two, their distinctness, at least in formal terms, seems to be greater than ever before.

The aim of this article is to attempt to characterize these two disciplines, i.e. economics and finance, as well as management and quality studies, and in particular to identify the place of these two disciplines in relation to each other and their links with other disciplines. To achieve this goal, data published on 31 July 2019, constituting a list of scientific journals, were used ${ }^{7}$.

\footnotetext{
6 According to the list of powers of units to award academic degrees from the POL-on database (https://polon.nauka.gov.pl/opi/aa/ck/stnauk/upr?execution=e3s1, accessed on 02.11.2019).

7 http://www.bip.nauka.gov.pl/akty-prawne-mnisw/komunikat-ministra-nauki-i-szkolnictwa-wyzszego-z-dnia31-lipca-2019-r-w-sprawie-wykazu-czasopism-naukowych-i-recenzowanych-materialow-z-konferencjimiedzynarodowych-wraz-z-przypisana-liczba-punktow.html (accessed on 2.11.2019).
} 
Due to the way the list was developed (it constitutes a certain consensus developed in teams of experts representing a particular discipline), it can be assumed, that it reflects quite well the relationships between particular disciplines and their perception by the scientific community.

\section{Methods}

The relationship between disciplines and journals is many-to-many, i.e. each discipline can be assigned to multiple journals and each journal can have multiple disciplines. Consequently, a simple quantitative specification of all disciplines assigned to journals in economics and finance, as well as management and quality studies, will give a much simplified picture of their links with other disciplines. For this reason, it was decided to use network analysis methods that allow for graphical representation and quantitative analysis of the complex relationships between elements, enabling them to be better understood (Otte and Rousseau, 2002; Ivens et al., 2016; Vincenot, 2018; Janik et al., 2020).

The starting point for network analysis is the mathematical structure of the graph $G(V, E)$, which consists of vertices $(V)$ and edges $(E)$. In this case, the vertices represent scientific disciplines. An edge joining two vertices means that there is a journal in the list that has assigned both disciplines represented by these vertices (Figure 1). Edges in the graph can have weights assigned to them, representing the strength of relationship (Newman, 2004) - for edges connecting disciplines, it will be the number of common journals.

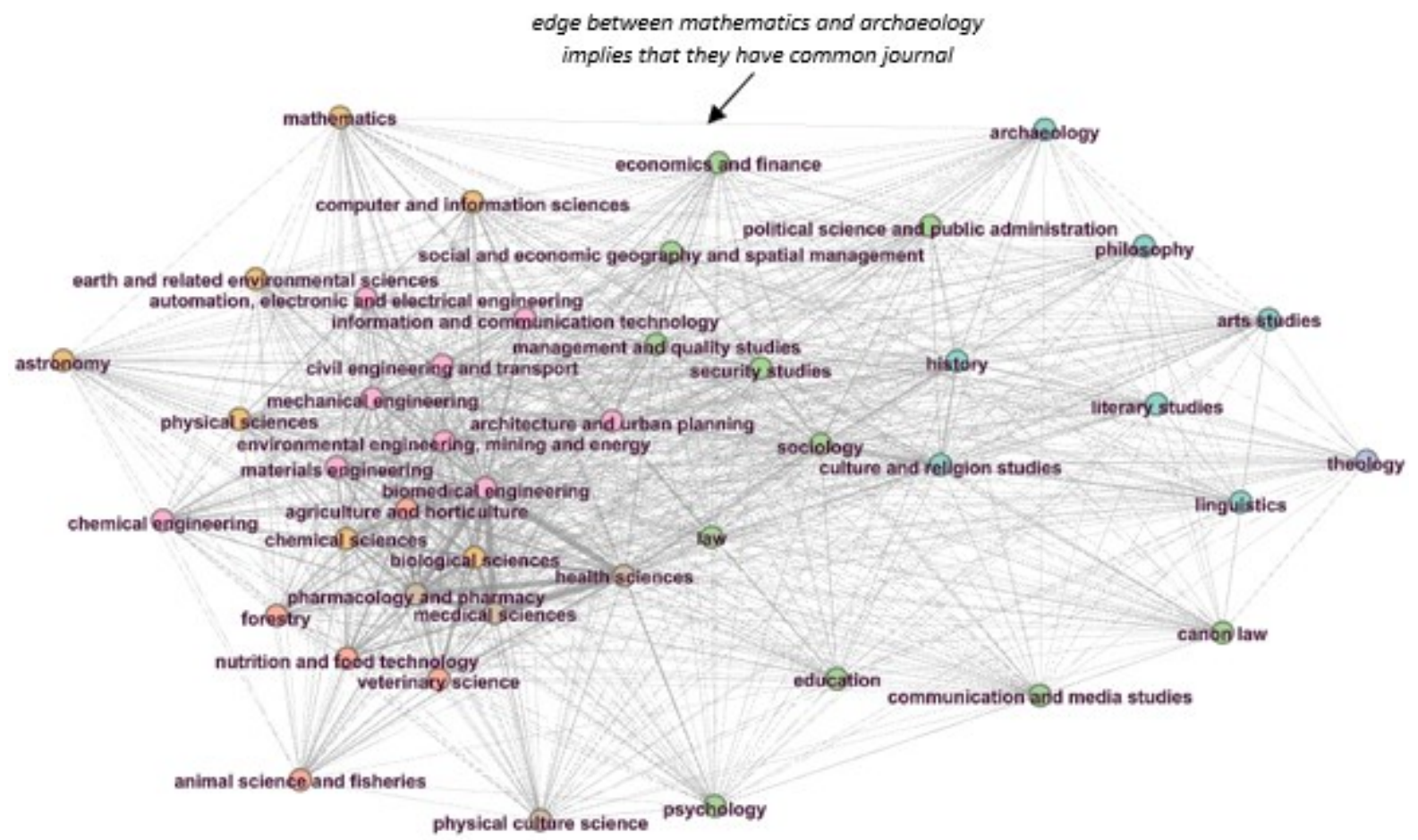

Figure 1. The network showing all the links between disciplines (the colors differs between fields). 
For graphs, it is possible to calculate many different indicators that characterize the whole network or individual vertices. The most important of them are (Otte and Rousseau, 2002):

- density - the ratio of the number of edges in a graph to the number of all possible edges; density equal to 1 means that every vertex in a graph is connected to every other vertex,

- degree of a vertex - the number of other vertices, to which the vertex is directly connected (in other words: the number of incidental edges to the vertex),

- closeness centrality - the reciprocal of the average length of the vertex (measured by the number of edges) to all other vertices; a higher value means that the vertex occupies a more central position in the network,

- betweenness centrality - the total frequency (calculated after all pairs of vertices in the network) with which a vertex appears in the shortest paths between pairs of other vertices; a high value of this coefficient means that a particular vertex acts as an "intermediary" in relationships between other units.

The listed indicators for the individual vertices are examples of the so-called centrality measures. They make it possible to compare the position of units in the network and inform about their involvement in relations (Batorski, and Zdziarski, 2009).

An important issue in the case of the network is also its graphic representation. An appropriate arrangement of vertices allows to illustrate the dependencies and structure of relations within the network, which would remain undisclosed if described by numbers alone. In this article, the ForceAtlas algorithm (Jacomy et al., 2014), which is implemented in Gephi program (Bastian et al., 2009), is used to visualize the network. The algorithm is based on two forces: attracting close vertices and repelling more distant vertices (the algorithm may also take into account the weights of edges between vertices). The resulting layout of network reflects well the relations between vertices and their position in relation to each other.

Another important feature of network analysis is the community detection, i.e. groups of vertices that for some reasons should be considered more interrelated with each other than with other vertices. There are many approaches to community detection in networks, thus groups can be identified in many different ways in a particular network (Tang, and Liu, 2010; Bedi, and Sharma, 2016). In the next part of the article, the algorithm presented in (Blondel et al., 2008) is used to identify similar groups of the disciplines.

\section{Results}

In the first step, a network was built on the basis of all data from the list of journals (Figure 1). This network showed a very high value of the density indicator (0.958), which meant that almost all disciplines had some kind of common journals (only 40 out of 946 of all possible pairs of such disciplines did not have any). Therefore, it was decided to limit the number of 
edges by taking into account the share of common journals in all the journals to which a particular discipline was assigned. Further analysis assumed, that there is a link between disciplines A and B, if common journals constitute at least $10 \%$ of journals of discipline A or at least $10 \%$ of journals of discipline B. It is worth noting here the differences in the number of journals assigned to particular disciplines. The largest number of journals $(10,641)$ was assigned to biomedical engineering, and the smallest (492) to theology. Due to this, the assumption of a certain level of share of common journals (in this case 10\%), rather than a certain absolute number, seems justified.

\subsection{Quantitative comparison of common journals in disciplines}

Tables 1 and 2 show a quantitative specification of journals by the following disciplines: management and quality studies (Table 1) and economics and finance (Table 2), respectively, which are common to other disciplines. The results are presented according to the number of journals in descending order. The first line of both tables contains the number of journals from each of these two disciplines. The tables present only those disciplines, for which the common share of journals accounted for at least $10 \%$.

Table 1.

Specification of journals from particular disciplines common to the discipline of management and quality studies

\begin{tabular}{|c|c|c|c|}
\hline Discipline & $\begin{array}{l}\text { \% share in the discipline of } \\
\text { management and quality } \\
\text { studies }\end{array}$ & $\begin{array}{l}\text { \% share in } \\
\text { the second } \\
\text { discipline }\end{array}$ & number \\
\hline management and quality studies & 100 & 100 & 3532 \\
\hline economics and finance & 31.57 & 73.36 & 1115 \\
\hline sociology & 21.77 & 25.73 & 769 \\
\hline information and communication technology & 19.9 & 31.65 & 703 \\
\hline architecture and urban planning & 18.01 & 26.64 & 636 \\
\hline biomedical engineering & 18.01 & 5.98 & 636 \\
\hline $\begin{array}{l}\text { social and economic geography and spatial } \\
\text { management }\end{array}$ & 17.92 & 46.92 & 633 \\
\hline security studies & 14.35 & 28.25 & 507 \\
\hline computer and information sciences & 13.17 & 32.31 & 465 \\
\hline health sciences & 12.51 & 5.03 & 442 \\
\hline mechanical engineering & 12.49 & 14.9 & 441 \\
\hline culture and religion studies & 11.83 & 12.54 & 418 \\
\hline environmental engineering, mining and energy & 11.3 & 12.5 & 399 \\
\hline civil engineering and transport & 10.84 & 13.43 & 383 \\
\hline political science and public administration & 8.47 & 25.49 & 299 \\
\hline automation, electronic and electrical engineering & 7.16 & 14.17 & 253 \\
\hline communication and media studies & 6.26 & 31.48 & 221 \\
\hline education & 5.63 & 14.55 & 199 \\
\hline law & 5.58 & 13.59 & 197 \\
\hline mathematics & 5.44 & 16.89 & 192 \\
\hline psychology & 4.42 & 13.78 & 156 \\
\hline physical culture science & 3.91 & 15.77 & 138 \\
\hline
\end{tabular}


Table 2.

Specification of journals from particular disciplines common to the discipline of economics and finance

\begin{tabular}{|l|r|r|r|}
\hline \multicolumn{1}{|c|}{ Discipline } & $\begin{array}{c}\text { \% share in the discipline of } \\
\text { economics and finance }\end{array}$ & $\begin{array}{c}\text { \% share in the } \\
\text { second discipline }\end{array}$ & number \\
\hline economics and finance & 100 & 100 & 1520 \\
\hline management and quality studies & 73.36 & 31.57 & 1115 \\
\hline $\begin{array}{l}\text { social and economic geography and spatial } \\
\text { management }\end{array}$ & & & \\
\hline sociology & 27.11 & 30.54 & 412 \\
\hline information and communication technology & 24.67 & 12.55 & 375 \\
\hline security studies & 12.57 & 8.6 & 191 \\
\hline architecture and urban planning & 12.37 & 10.47 & 188 \\
\hline political science and public administration & 12.04 & 7.67 & 183 \\
\hline health sciences & 11.38 & 14.75 & 173 \\
\hline culture and religion studies & 10.66 & 1.84 & 162 \\
\hline mathematics & 10.53 & 4.8 & 160 \\
\hline history & 10.46 & 13.98 & 159 \\
\hline environmental engineering, mining and energy & 10.2 & 5.48 & 155 \\
\hline
\end{tabular}

First of all, it should be noted, that both disciplines, i.e. management and quality studies, as well as economics and finance, are the most interlinked. The number of journals assigned to both disciplines is 1,115 . The fact of the disproportion in the number of journals assigned to each of these disciplines is also worth noting - the discipline of management and quality studies has been assigned to more than twice as many journals as the discipline of economics and finance. Therefore, common journals constitute about $32 \%$ of all journals of the first one and as much as $73 \%$ of all journals of the second one. In both cases, the first three closest disciplines (in terms of a common number of journals) include sociology (2nd place for management and quality studies and 3rd place for economics and finance). The difference is, however, in the case of the third discipline, which is in the top three of the closest disciplines. In case of economics and finance, it is social and economic geography and spatial management, while for management and quality studies, it is information technology and communication (i.e. a discipline of engineering and technology field). In the case of economics and finance, there is also a clear decrease in the share of common journals with other disciplines - the fourth position is held by journals with the assigned discipline of information and communication technology, but their number is almost twice as low as for the third position of sociology. In case of management and quality studies, the decrease in the share of common journals is more moderate, followed by two other disciplines of engineering and technology field: archeology and urban planning, as well as biomedical engineering. In general, the group of disciplines with the highest number of common journals with management and quality studies includes as many as 7 disciplines of engineering and technology field, whereas for economics and finance there are only 3 such disciplines. It is also worth noting the common journals in the discipline of mathematics. Although there are slightly more of them in the management and quality studies (191, compared to 159 in economics and finance), their share in journals for economics and finance is almost two times higher. 


\subsection{Network analysis of disciplines}

Figure 2 shows the network of relationships between disciplines according to previously adopted criteria (an edge between two disciplines occurs when common journals account for at least $10 \%$ of all journals in one of them). The vertex size represents the number of journals, to which a particular discipline is assigned. The colors of vertices indicate the field to which the discipline represented by a particular vertex belongs. The width of edges illustrates the number of common publications in disciplines. The vertices are distributed using the ForceAtlas algorithm, taking into account the weight of edges. For greater clarity, the disciplines under analysis are marked with red arrows. The density of the network is 0.359 .

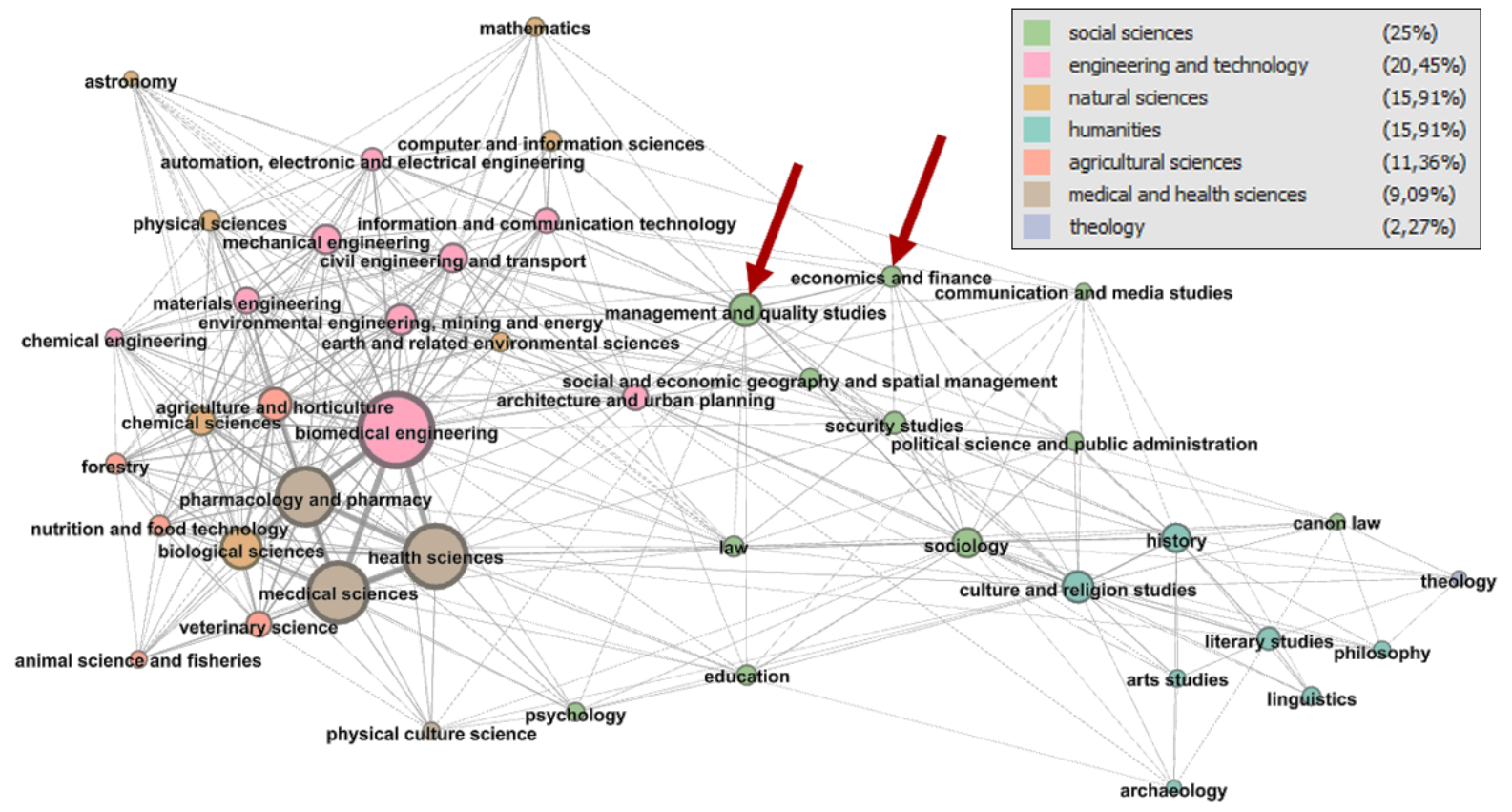

Figure 2. The network of inter-disciplinary links (an edge between disciplines means that common journals account for at least $10 \%$ of all journals in one of these disciplines).

What draws attention, first and foremost, is the distribution and grouping of disciplines, mostly in accordance with fields. On the right ${ }^{8}$ are disciplines of the humanities (with an extremely located theology), next to them are the social sciences, and even further are the engineering and technology disciplines. It is also worth noting the group of disciplines that have been assigned to the largest number of journals, i.e. biomedical engineering (engineering and technology field) and disciplines in the field of medical and health sciences: health sciences, medical sciences, as well as pharmacology and pharmacy. These disciplines are strongly interlinked, as shown by the width of the edge. An interesting, but at the same time not very surprising fact, is the not-too-distant position from these disciplines of psychology, despite belonging to the social sciences. The most scattered and heterogeneous seem to be the disciplines belonging to the field of natural sciences (orange). It is worth pointing out, that this

\footnotetext{
${ }^{8}$ Left/right or up/down orientation is irrelevant in this case. The position of particular disciplines in relation to each other is important.
} 
field was created by consolidating disciplines belonging to two different areas in the previous classification.

As far as the disciplines of interest are concerned, they are close together, on the left side of the social sciences. However, their position is different. In the case of economics and finance, there are links mainly with other social sciences (Figure 3). Also noteworthy is the link with mathematics, as the only discipline of natural sciences (it is also worth noting that the only disciplines of social sciences linked to mathematics are economics and finance, as well as management and quality studies).

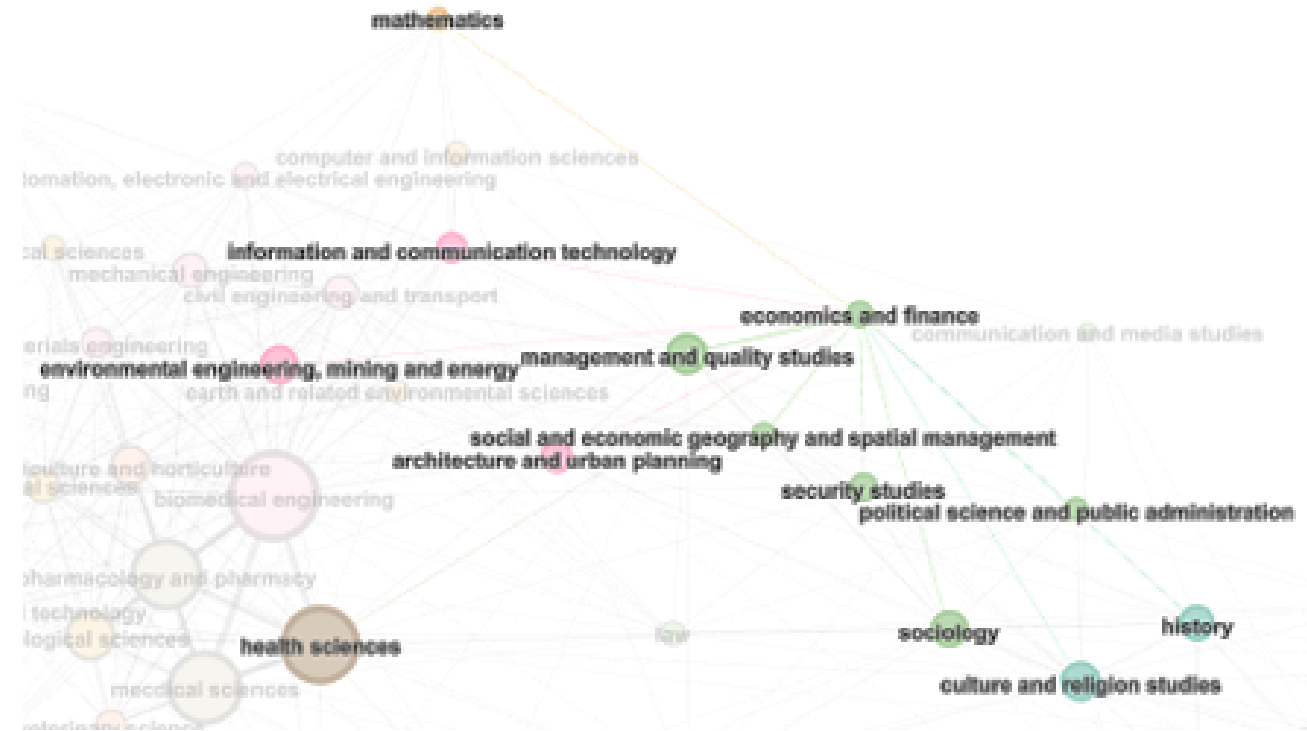

Figure 3. The network of relationships of the discipline of economics and finance.

The position of the discipline of management and quality studies is much more central (Figure 4), and its relationships are distributed fairly evenly between the "soft" (social sciences) and "hard" sciences. In the immediate vicinity of management and quality studies, apart from economics and finance, there are also: social and economic geography, security studies, architecture and urban planning, as well as disciplines related to information and communication technology (ICT) - information and communication technology, as well as computer and information sciences. 


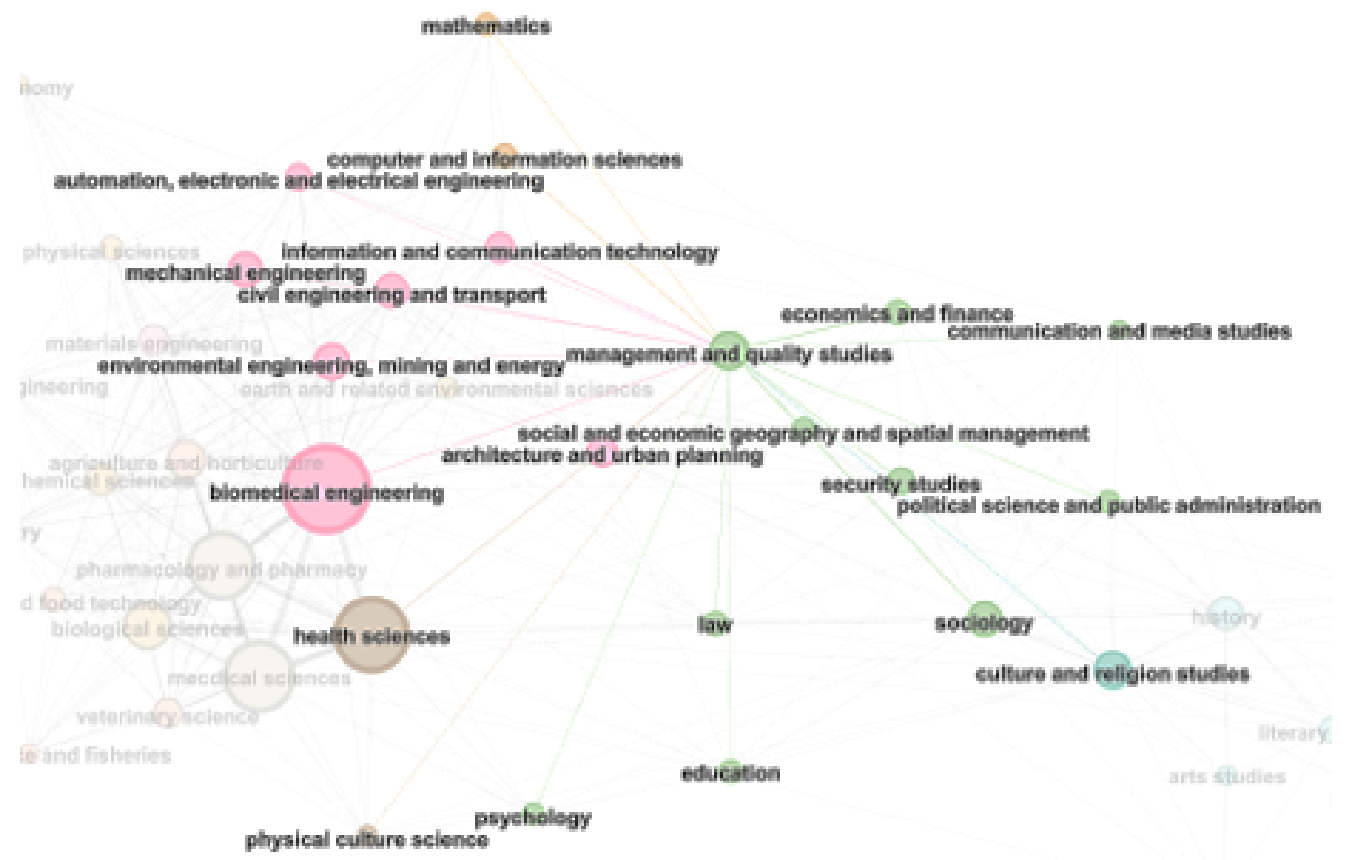

Figure 4. The network of relations of the discipline of management and quality studies.

Much more central position of management and quality studies is also confirmed by centrality measures. Table 3 shows their values and rank positions, i.e. the place where a discipline is located in terms of a particular measure among all disciplines. Management and quality studies are at the forefront of disciplines here, while economics and finance are at about halfway point. It is worth noting, that the number of journals to which a particular discipline is assigned does not translate directly into centrality measures. As an example, the table also includes measures for the discipline of medical sciences, which - with a much higher number of journals - is characterized by significantly lower centrality rates than the management and quality studies.

Table 3.

Centrality measures (and total number of journals) in the disciplines of management and quality studies, economics and finance, and medical sciences

\begin{tabular}{|l|c|c|c|c|c|c|c|c|}
\hline \multirow{2}{*}{\multicolumn{1}{|c}{ Discipline }} & \multicolumn{2}{|c|}{ no. of journals } & \multicolumn{2}{c|}{$\begin{array}{c}\text { closeness } \\
\text { centrality }\end{array}$} & \multicolumn{2}{c|}{$\begin{array}{c}\text { betweenness } \\
\text { centrality }\end{array}$} & \multicolumn{2}{c|}{ degree } \\
\cline { 2 - 10 } & value & rank & value & rank & value & rank & value & rank \\
\hline management and quality studies & 3532 & 7 & 0.66 & 6 & 34.03 & 7 & 21 & 11 \\
\hline economics and finance & 1520 & 23 & 0.58 & 19 & 10.70 & 19 & 12 & 27 \\
\hline medical sciences & 8348 & 3 & 0.61 & 16 & 11.36 & 18 & 19 & 14 \\
\hline
\end{tabular}

Figure 5 shows the same network, but this time the colors of vertices are assigned to groups which were identified based on the community detection algorithm described in (Blondel et al., 2008). The size of vertices here corresponds to their degree, i.e. the number of edges of that vertex. 


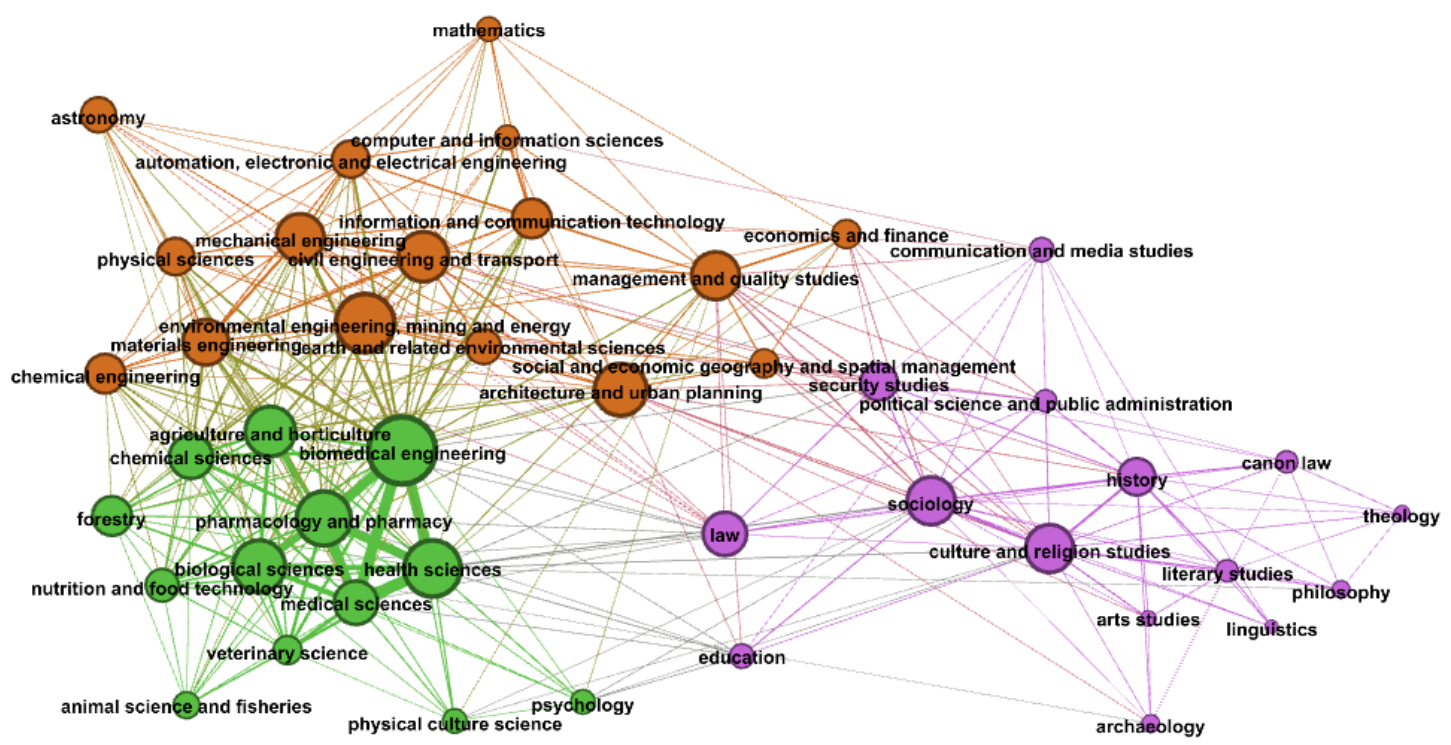

Figure 5. The network of relations between disciplines divided by group detection algorithm.

As can be seen, three groups have been identified, which only partially correspond to the field division of disciplines. Both management and quality studies, as well as economics and finance, were in one group with the majority of engineering and technical sciences, as well as natural sciences. The second group consists mainly of medical and health sciences and agriculture sciences, but also biomedical engineering and psychology. The third group includes all the humanities and most social sciences.

\section{Discussion}

The presented results confirm - which is not surprising - a strong link between the disciplines of economics and finance, as well as management and quality studies. They also allow us to point out some of the differences between them. The discipline of economics and finance is particularly strongly linked with the discipline of social and economic geography and spatial management. This is most likely due to the fact that some of the issues previously dealt with by economics in the new classification have been included in this discipline. There are rather few links with the technical and natural sciences and they relate to disciplines such as mathematics, information technology and communication, environmental engineering, mining and energy, as well as architecture and urban planning. This is not the case for management and quality studies, which is more closely linked to disciplines outside social sciences. It is interesting to note, that in the group of disciplines closest to the management and quality studies are: information technology and communication, as well as architecture and urban planning. However, there are no disciplines which, according to the new division, cover 
some of the issues from the former discipline of commodity science (i.e. materials engineering, as well as nutrition and food technology).

Also, the position of these two disciplines in the network (representing links between disciplines through common journals) is different. The relationships between the discipline of management and quality studies are much more diversified, and the measures of its centrality are much higher than those of economics and finance, very high also in comparison with most other disciplines. The high value of closeness centrality means that management and quality studies is closely linked to most other disciplines. The value of betweenness centrality, in turn, indicates the role of a kind of "intermediary" between disciplines, in particular between the sciences commonly referred to as "soft" and "hard" (as evidenced by the position of management and quality studies on the network).

Noteworthy is also the assignment of former economic disciplines by the group detection algorithm in networks to a group which includes mainly the disciplines of engineering and technology, as well as natural sciences. However, when interpreting such an assignment, one should be cautious. The division into groups in networks may be different, depending on the algorithm used and the adopted measures of similarity and distance. This is an example of the so-called unsupervised learning, in which there are no clear criteria for the best division. However, the obtained result confirms, in some way, the separation of economics and finance, as well as management and quality studies from other disciplines of social sciences.

It should be noted, that the results obtained are based only on a quantitative approach to the relationships between disciplines, determined on the basis of the number of common journals. It was assumed, that such a relationship exists if common journals constitute at least $10 \%$ of all journals to which a particular discipline has been assigned, regardless of their subject matter or rank. Therefore, the results obtained should not be used to draw too far-reaching conclusions, e.g. on the differences between the disciplines of economics and finance, as well as management and quality studies in methods, subject matter or facilities under analysis. However, the results of the analysis give a general picture of both disciplines and indicate their relation with other sciences, including their position in the scientific landscape.

\section{Summary}

The article presents the results of analysis, both quantitative and network, of the disciplines of economics and finance, as well as management and quality studies, based on the data from the list of journals published on 31 July 2019. The obtained results allowed to characterize the similarities and differences between the two disciplines, including the identification of their main relations with other scientific disciplines. The analysis was based primarily on the number of common journals assigned to a particular pair of disciplines, which made it possible to 
present the network of links between the disciplines in graphical form. It can be treated as a specific landscape of science, or at least how it is perceived by Polish researchers, who were members of teams preparing a list of journals in particular disciplines.

The analysis carried out is obviously of a limited nature. Further research may take into account, for example, different research trends and approaches within the disciplines themselves. It would be interesting to compare keywords in articles from common journals, as well as to analyze the text of titles or the content of their abstracts. This could reveal new relationships between disciplines, as well as identify common sub-disciplines, and thus deepen their characteristics on the basis of objective data. Additionally, other unsupervised machine learning algorithms, such as dimension reduction (Jordan, and Mitchell, 2015; Wang et al., 2016) or clustering methods (Murtagh, and Contreras, 2012; Verma et al., 2012) could be used to identify groups of closely connected disciplines.

\section{Acknowledgements}

This paper was financed from the resources of the Silesian University of Technology, project no. BK-235/ROZ-1/2020 (13/010/BK_20/0042).

\section{References}

1. Bastian, M., Heymann, S., and Jacomy, M. (2009, March). Gephi: an open source software for exploring and manipulating networks. In Third international AAAI conference on weblogs and social media.

2. Batorski D., and Zdziarski M. (2009). Analiza sieciowa i jej zastosowania w badaniach organizacji i zarządzania. Problemy Zarządzania, 7(6), pp. 157-184.

3. Bedi, P., and Sharma, C. (2016). Community detection in social networks. Wiley Interdisciplinary Reviews: Data Mining and Knowledge Discovery, 6(3), pp. 115-135.

4. Gorynia, M., and Kowalski, T. (2013). Nauki ekonomiczne i ich klasyfikacja a wyzwania współczesnej gospodarki, Ekonomista, 4, pp. 457-474.

5. Ivens, A.B., von Beeren, C., Blüthgen, N., and Kronauer, D.J. (2016). Studying the complex communities of ants and their symbionts using ecological network analysis. Annual Review of Entomology, 61, pp. 353-371.

6. Jacomy, M., Venturini, T., Heymann, S., and Bastian, M. (2014). ForceAtlas2, a continuous graph layout algorithm for handy network visualization designed for the Gephi software. PloS one, 9(6), p. e98679. 
7. Janik, A., Ryszko, A., and Szafraniec, M. (2020). Scientific Landscape of Smart and Sustainable Cities Literature: A Bibliometric Analysis. Sustainability, 12(3), p. 779.

8. Jordan, M.I., and Mitchell, T.M. (2015). Machine learning: Trends, perspectives, and prospects. Science, 349(6245), pp. 255-260.

9. MNiSW, Nowe rozporządzenie ws. dyscyplin - to rzetelna ocena badań naukowych, 20.09.2018. Retrieved from https://www.gov.pl/web/nauka/nowe-rozporzadzenie-wsdyscyplin-to-rzetelna-ocena-badan-naukowych, 02.11.2019.

10. Murtagh, F., and Contreras, P. (2012). Algorithms for hierarchical clustering: an overview. Wiley Interdisciplinary Reviews: Data Mining and Knowledge Discovery, 2(1), pp. 86-97.

11. Newman, M.E. (2004). Analysis of weighted networks. Physical review E, 70(5), p. 056131.

12. OECD, Revised field of science and technology (fos) classification in the frascati manual, 2007. Retrieved from https://www.oecd.org/science/inno/38235147.pdf, 02.11.2019.

13. Otte, E., and Rousseau, R. (2002). Social network analysis: a powerful strategy, also for the information sciences. Journal of information Science, 28(6), pp. 441-453.

14. Sudoł, S. (2016). Zarządzanie jako dyscyplina naukowa. Przeglad Organizacji, 4, pp. 4-11.

15. Tang, L., and Liu, H. (2010). Graph mining applications to social network analysis. In: Managing and Mining Graph Data (pp. 487-513). Boston, MA: Springer.

16. Verma, M., Srivastava, M., Chack, N., Diswar, A.K., and Gupta, N. (2012). A comparative study of various clustering algorithms in data mining. International Journal of Engineering Research and Applications (IJERA), 2(3), pp. 1379-1384.

17. Vincenot, C.E. (2018). How new concepts become universal scientific approaches: insights from citation network analysis of agent-based complex systems science. Proceedings of the Royal Society B: Biological Sciences, 285(1874), p. 20172360.

18. Wang, S., Lu, J., Gu, X., Du, H., and Yang, J. (2016). Semi-supervised linear discriminant analysis for dimension reduction and classification. Pattern Recognition, 57, pp. 179-189. 